\title{
Agricultura familiar, organização de produtores e desenvolvimento territorial: oportunidades e ameaças em experiências agroalimentares no Estado de Santa Catarina (Brasil)'
}

\author{
Valdir Roque Dallabrida \\ Universidade do Contestado \\ Julio José Plaza Tabasco \\ Universidad de Castilla-La Mancha \\ Ángel Raul Ruíz Pulpón \\ Universidad de Castilla-La Mancha
}

\section{Resumo}

A agricultura familiar situada em zonas periurbanas está demonstrando uma importante capacidade de adaptação nos atuais mercados agroalimentares, sustentada no esboço de estratégias que aportam valor agregado ao produto final, destacando a vinculação territorial, a qualidade e o saber-fazer. Por outro lado, atende à demanda de consumo em cidades próximas mediante uma relação de proximidade, o que transforma essa agricultura em exemplos de resiliência frente à pressão de outros tipos de cultivo de mercado. A partir do estudo de duas experiências agroalimentares de tipo familiar que ocorrem no Estado de Santa Catarina (Brasil), teve-se como objetivo analisar sua capacidade de adaptação aos entornos urbanos e, em consequência, seu papel no desenvolvimento territorial. Tratase, a primeira, da elaboração do queijo Kochkäse, no Vale do Itajaí e, a segunda, da maricultura de ostras no litoral de Florianópolis. Metodologicamente, foram realizadas entrevistas com representantes dos produtores, demonstrando, como principais resultados, a importância da diferenciação produtiva e dos métodos de produção tradicionais para obter produtos específicos que se convertem em signos distintivos territoriais, contribuindo para a geração de alternativas de renda e a revalorização da identidade, com impactos no desenvolvimento territorial. Esse papel poderia ser reforçado mediante a criação de formas de reconhecimento da

1 Este artigo, na sua versão inicial apresentado no VIII Seminário Internacional sobre Desenvolvimento Regional (UNISC/2017), resume resultados do projeto de pesquisa

Signos Distintivos Territoriais e Indicação Geográfica: um estudo sobre os desafios e perspectivas como alternativa de Desenvolvimento Territorial, com financiamento do CNPq. 
identidade e especificidade, como o instituto da Indicação Geográfica, ou outras formas de associativismo que permitam compartilhar um projeto comum. Em contrapartida, evidencia-se como sendo a falta de substituição geracional o principal desafio a resolver nos próximos anos.

Palavras-chave: Agricultura Familiar. Agricultura Periurbana. Associativismo Territorial. Desenvolvimento Territorial.

\section{Family farming, producers organization and regional development: opportunities and threatens in agrifood experiences in Santa Catarina State (Brazil)}

\section{Abstract}

The family farming located in peri-urban zones is showing an important capacity of adaptation in current agri-food Market, based in the outline of strategies that contributes for the final product aggregated value, highlighting the territorial entailment to quality and know-how to do. On the other hand, it caters to the consume demand in nearby cities by a proximity relation, which turns this kind of agriculture a resilience example face to other types of cultivation in the Market. From the study of two agri-food family farming experiences, situated in the state of Santa Catarina (Brazil), the aim was to analyze its capability of adapting to urban surrounding area, and, as a consequence, its role in territorial development. The first experience is the elaboration of Kochkäse cheese, in Itajaí Valley, and the second, the oyster mariculture, in Florianópolis coast. Methodologically, interviews with the commercial representative of producers were made, showing, as main results, the importance of productive distinction and the traditional methods of production to obtain specific products that turn it selves into territorial distinguishing signs, contributing for the generation of alternative income and identity enhancement, impacting on territorial development. This role could be reinforced by the creation of a new recognition of identity and specificity, like the Geographic Institute, or other ways of associativism that allow sharing a common project. Conversely, it becomes clear as being the lack of generational substitution the main challenge to be solved in the next years.

Keywords: Family Farming. Peri-urban Agriculture. Territorial Associativism. Territorial Development.

\section{Agricultura familiar, organización de productores y desarrollo territorial: oportunidades y amenazas en experiencias agroalimentarias en el Estado de Santa Catarina (Brasil)}

\section{Resumen}

La agricultura familiar situada en zonas periurbanas demuestra una importante capacidad de adaptación en los actuales mercados agroalimentarios, sustentada en el esbozo de estrategias que aportan valor agregado al producto final, destacando la vinculación territorial, la calidad y el saber hacer. Por otro lado, atiende la demanda de consumo en ciudades cercanas mediante una relación de proximidad, lo que transforma este tipo de agricultura en ejemplos de resiliencia frente a la presión de otros tipos de cultivo de mercado. A partir del estudio de dos experiencias agroalimentarias de tipo familiar que ocurren en el Estado de Santa Catarina (Brasil), se tuvo como objetivo analizar su capacidad de adaptación a los entornos urbanos y, en consecuencia, su papel en el desarrollo territorial. Se trata, la primera, en la elaboración del queso Kochkäse, en el Valle del Itajaí y, la segunda, la maricultura de 
ostras en el litoral de Florianópolis. Metodologicamente, se realizaron entrevistas con representantes de los productores, demostrando, como principales resultados, la importancia de la diferenciación productiva y de los métodos de producción tradicionales para obtener productos específicos que se convierten en signos distintivos territoriales, contribuyendo para la generación de alternativas de renta y la revalorización de la identidad, con impactos en el desarrollo territorial. Este papel podría reforzarse mediante la creación de formas de reconocimiento de la identidad y la especificidad, como el instituto de la Indicación geográfica, u otras formas de asociativismo que permitan compartir un proyecto común. En cambio, se evidencia la falta de sustitución generacional, como el principal desafío a resolver en los próximos años.

Palabras clave: Agricultura Familiar. Agricultura Periurbana. Asociativismo Territorial. Desarrollo Territorial.

\section{INTRODUÇÃO}

As áreas periurbanas atuais se definem pela heterogeneidade de usos dos solos e pela complexidade das dinâmicas sociais e econômicas derivadas da inter-relação entre o espaço urbano e rural. A diversidade de atividades e de formas de ocupação do espaço tem sido acelerada pelo processo de globalização, que tem resultado numa profunda reestruturação das atividades econômicas do meio rural.

No que se refere às atividades agropecuárias, observa-se como têm sido expostas às influências de caráter contraditório, dependendo diretamente do tipo de relação existente com as cidades. Uma primeira é de caráter negativo, que indica a pressão de usos do solo eminentemente urbanos (residencial, lazer, infraestruturas, empresarial...), sobre as explorações agrárias. Dessa forma, o território não urbanizado e contíguo se converteria em objeto potencial de anexação, o que interessa somente pelo seu valor urbanístico (ÁVILA, 2004), com isso, resultando em situações de alijamento social, em função da destinação do solo urbano para outros usos mais lucrativos (SEGRELLES, 2015). Essas relações de dominação ou de depredação são facilmente constatáveis na declinação do número de explorações agrárias de distintos países, cujo modelo tem sido orientado de forma lógica à dedicação em serviços de tempo parcial, diante da forte demanda de empregos das cidades. Diante desse tipo de ameaças, os cultivos agrícolas periurbanos têm demonstrado uma importante capacidade de adaptação derivada de sua proximidade ao meio urbano (MENDOZA, 1987), em que está desempenhando um papel fundamental a aposta pela diferenciação produtiva e pela revalorização dos territórios agrários, como lugares vinculados com a sustentabilidade e com a manutenção da população (CAPEL, 1994). É neste contexto que esse tipo atividades agrárias experimenta outras dinâmicas, a priori, de caráter positivo, assentadas na modernização, na diferenciação, na inovação e na busca da qualidade que satisfaçam à demanda de consumo dos núcleos urbanos. Portanto, cada vez mais estas experiências aproveitam a proximidade dos consumidores que estão sensibilizados pela qualidade e pela seguridade alimentar. 
Essas oportunidades, para citar o exemplo europeu, estão agrupadas no Ditame do Comitê Econômico e Social Europeu sobre agricultura periurbana, publicado em 2004 (NAT, 2004). Para a valorização das funções meio-ambientais, sociais e econômicas da agricultura periurbana, o Ditame incorpora seu papel na ordenação do território, já que a mesma impede o crescimento ilimitado das cidades, gera paisagens culturais e humaniza os entornos urbanos. Também aponta as potencialidades que presumiria contribuir para 0 desenvolvimento territorial, a criação de partenariados ${ }^{2}$ e outras formas de organização social, como redes de cooperação entre agentes públicos e privados, a partir da conjugação de interesses e de ações comuns ligadas à base territorial e aos recursos naturais.

Em definitivo, um modelo de agricultura que exerça uma função-chave na conservação de paisagens multifuncionais de entorno urbano, contribuindo para o abastecimento de alimentos de proximidade e garantindo sua função ambiental porque se garante a biodiversidade (YACAMÁN e MATA, 2014; SEGRELLES, 2015). A atividade agrária também tem gerado um importante patrimônio cultural e imaterial que pode ser revalorizado e servir de complemento ao desenvolvimento de outras atividades, como o turismo especializado, segundo a Carta da Agricultura periurbana para a preservação, a ordenação, o desenvolvimento e a gestão dos espaços agrários periurbanos, publicada em 2010 em Casteldefells (Barcelona), que envolve grande parte dos aspectos assinalados no Ditame mencionado.

A diferenciação da produção e a aposta por qualidade são entendidas como vantagens comparativas que resultam chave nos mercados agrários atuais (PECQUEUR, 2009). Ambas se constituem em indiscutíveis fatores de desenvolvimento territorial ao congregar, como qualquer iniciativa agroalimentar fundamentada em características específicas, comedimentos de tipo ambiental, social, econômico e institucional (SÁNCHEZ et al. 2009; RUÍZ e PLAZA, 2015). Do ponto de vista ambiental, a mencionada promoção da biodiversidade em espaços de forte pressão urbanística amplifica o papel desempenhado pelas condições geográficas na obtenção de um produto com personalidade própria, com uma aparência e com um sabor característicos; socialmente, porque são consequência de um saber-fazer e uma herança comuns, que fazem parte da identidade regional e da história do lugar que cresce e deve diferenciar-se em um mundo global, além das oportunidades para o fomento da governança territorial, que supõe a criação de distintas fórmulas de associativismo; economicamente, ao dotar os produtos de uma maior competitividade derivada de seu valor agregado; e institucionalmente, pelo apoio normativo e administrativo e as oportunidades que esboça a configuração

2 Termo utilizado para se referir a coalizões entre organizações parceiras, que buscam o desenvolvimento de um determinado lugar de uma forma participativa, por meio de um programa de ação conjunta. 
Agricultura familiar, organização de produtores e desenvolvimento territorial: oportunidades e ameaças em experiências agroalimentares no Estado de Santa Catarina (Brasil)

de signos distintivos territoriais com potencial de certificação (DALLABRIDA, RUÍZ e PLAZA, 2016). refletir.

É sobre essas oportunidades, com seus desafios, que se pretende

A título de hipótese, considera-se que a proximidade das atividades agropecuárias das grandes cidades supõe uma oportunidade para sua adequação às novas demandas dos núcleos urbanos de produtos diferenciados e de qualidade, com isso, abrindo um amplo leque de oportunidades para este tipo de explorações, ao torná-las viável econômica, social e ambientalmente.

Assim, o objetivo aqui buscado é analisar a capacidade de adaptação de experiências de agricultura familiar desenvolvidas em entornos urbanos que, a partir do saber-fazer e da diversificação produtiva, estão desempenhando um interessante papel no desenvolvimento territorial ao serem viáveis econômica, social e ambientalmente. A primeira experiência agroalimentar está associada à elaboração de queijos tradicionais tipo Kochkäse, cuja relevância reside no peso da tradição e no saber-fazer; a segunda, trata-se da maricultura de ostras, nas proximidades da cidade de Florianópolis, que, com técnicas tradicionais de cultivo, oferece um produto com altos padrões de qualidade. A eleição dos dois casos se justifica porque são representativos das dinâmicas expostas no Ditame do Comitê Econômico e Social Europeu sobre agricultura periurbana (NAT, 2004), ao beneficiar-se da proximidade aos mercados urbanos e ao estabelecer possibilidades de organização entre os produtores que permitiriam, conjugados convenientemente, converter-se em estratégias de desenvolvimento territorial integrado.

\section{PROCEDIMENTOS METODOLÓGICOS}

A metodologia de estudo se baseia em critérios qualitativos a partir de entrevistas semiestruturadas, diretas, com os produtores, empresários e responsáveis pela gestão de cada uma das experiências, complementada por recursos bibliográficos e documentais. O questionário tem sido desenhado atendendo às dimensões sociais, econômicas, ambientais e institucionais, que definem esta classe de processos e já utilizadas em estudos anteriores (DALLABRIDA; RUÍZ e PLAZA, 2016). O Quadro 1 sintetiza as principais linhas temáticas abordadas no questionário utilizado. 
Quadro 1. Principais linhas temáticas abordadas no questionário

\begin{tabular}{|c|c|}
\hline Linha temática & Questões relativas a: \\
\hline Institucional & $\begin{array}{l}\text {-Papel das instituições no processo de organização } \\
\text {-Nível de relações com os governos locais e regionais }\end{array}$ \\
\hline Social & $\begin{array}{l}\text { - Nível de participação na tomada de decisões } \\
\text {-Serviços aos sócios } \\
\text {-Gestão de aspectos culturais e patrimoniais } \\
\text {-Atividades de proteção e/ou benefício } \\
\text {-Apoio a valores identitários } \\
\text {-Questões relacionadas com a estrutura de governança } \\
\text { - Questões de ordem e/ou conflitos legais } \\
\text {-Nível de socialização de benefícios entre os atores }\end{array}$ \\
\hline Econômica & $\begin{array}{l}\text {-Valoração por pertencer a um distintivo de qualidade } \\
\text {-Defesa dos interesses econômicos } \\
\text {-Fomento de práticas associadas à qualidade } \\
\text {-Incentivo de atividades turísticas }\end{array}$ \\
\hline Ambiental & $\begin{array}{l}\text {-Aspectos físicos, naturais, históricos e organizativos } \\
\text { - Questões relacionadas com a sustentabilidade das } \\
\text { experiências } \\
\text {-Estratégias de defesa de paisagens/cultivos tradicionais } \\
\text {-Produção agroecológica }\end{array}$ \\
\hline $\begin{array}{l}\text { Territoriais/Outros } \\
\text { aspectos }\end{array}$ & $\begin{array}{l}\text {-Desafios reconhecidos e superados } \\
\text {-Possível papel do instituto da Indicação Geográfica na } \\
\text { dinâmica territorial do desenvolvimento, caso venha ser } \\
\text { adotado } \\
\text {-Fatores de êxito assinalados pelos autores }\end{array}$ \\
\hline
\end{tabular}

Fonte: Elaboração própria dos autores (2017).

\section{CARACTERIZAÇÃO E ANÁLISES DE EXPERIÊNCIAS}

\subsection{O queijo tipo Kochkäse: histórico e contextualização no Vale do Itajaí}

Kochkäse é a denominação dada a um tipo de queijo que vem sendo tradicionalmente produzido e consumido pela população de origem alemã, residente em vários dos municípios do Médio Vale do Itajaí, no Estado de Santa Catarina (Brasil). Trata-se de um queijo cozido artesanalmente, com sabor inconfundível. Pode ser servido no pão, batata ou aipim (mandioca).

A base da produção dessa iguaria, o Kochkäse, está no leite cru desnatado. No processo de produção do Kochkäse, após a ordenha, o leite é drenado para retirada de material particulado e desnatado. Após desnate, o leite permanece em descanso quando coagula naturalmente. A coalhada é levada ao fogo para um leve aquecimento da massa e a mesma é colocada em sacos de nylon ou de algodão para drenagem do soro e formação do queijinho branco, produto também típico da região, muito utilizado para fabricação de cucas. O queijinho branco é então triturado em uma bacia e coberto com um pano para ser fermentado. O período de fermentação varia conforme as estações do ano, podendo ocorrer entre dois e sete dias, ocorrendo mais rapidamente no verão. A massa de queijo fermentada é levada para o 
Agricultura familiar, organização de produtores e desenvolvimento territorial: oportunidades e ameaças em experiências agroalimentares no Estado de Santa Catarina (Brasil)

cozimento quando a mesma apresentar coloração amarelada e odor característico. Durante o processo de cozimento, a massa precisa ser revolvida constantemente. O kochkäse estará pronto quando não forem visualizados grumos soltos e a massa se tornar uniforme, sendo então despejada em um recipiente para ser consumido ou comercializado (SILVA, 2013).

O Kochkäse, também chamado de Stinkkäse (queijo fedido) ou Stinky (cheiro forte), assim como tudo que diz respeito à culinária, é feito tradicionalmente, sendo passado seu saber-fazer de uma geração a outra. As mulheres agricultoras relataram terem aprendido com suas mães, que por sua vez aprenderam com suas avós e estas com as suas bisavós. Na primeira e segunda geração das avós e bisavós, ele era feito somente para a família. Com o aumento da bacia leiteira e da procura dos consumidores pelo produto, ele passou a ser comercializado, sendo considerado hoje o produto que oferece o maior retorno econômico para as famílias envolvidas na atividade da pecuária leiteira (SILVA, 2013).

Figura 1. Queijo cozido tipo Kochkäse

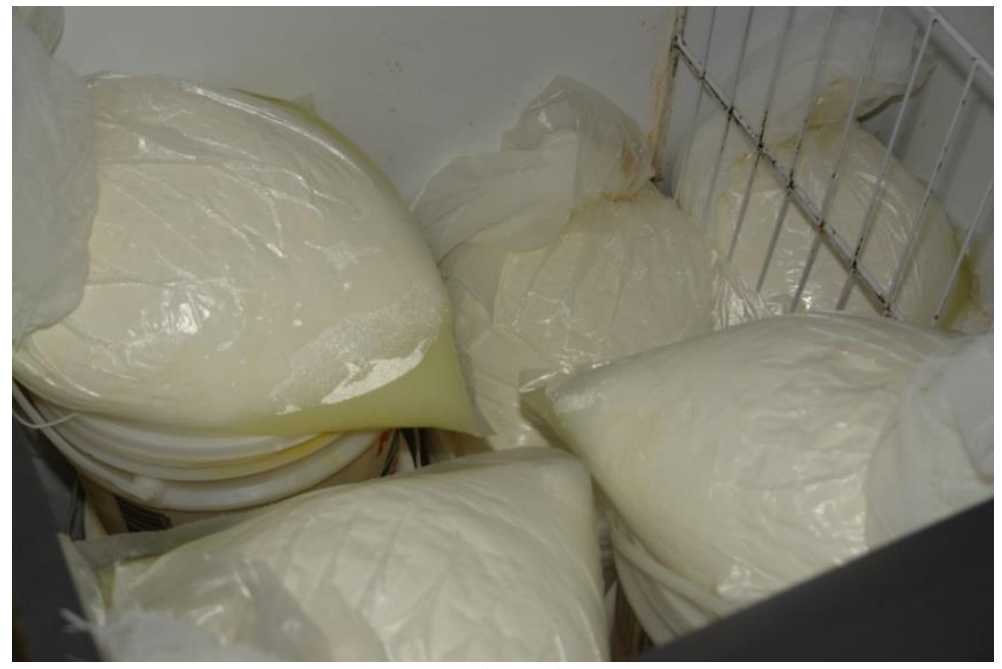

Fonte: Foto Julio Plaza Tabasco (2016).

Sobre sua origem histórica, segundo pesquisas já realizadas (SILVA, 2016), agricultores familiares provenientes da Pomerania, Mecklemburgo e Schleswig-Holstein, da Alemanha, no ano de 1850, ocuparam a região do Médio Vale do Itajaí (SC) como colonos. Esses e seus descendentes introduziram o queijo Kochkäse, o qual vem sendo tradicionalmente produzido e consumido regionalmente, sendo, portanto, considerado um queijo de origem alemã. Uma característica marcante do Vale do Itajaí ainda hoje é a presença de pequenas agroindústrias familiares que comercializam os produtos típicos da região em feiras municipais e regionais, nas quais o Kochkäse está constantemente presente. 
Segundo relata Silva (2016), apesar de poder ser considerado um produto integrado à identidade de grupos sociais do Vale do Itajaí (SC), o Kochkäse, enfrenta problemas com a vigilância sanitária que, considerando não atender aos parâmetros da legislação brasileira, ainda apresenta restrições e/ou impedimentos, para a comercialização de produtos produzidos com leite cru. Em 2013, o Ministério da Agricultura lançou a Instrução Normativa número 30 (BRASIL, 2013), que permitiu a comercialização de queijos feitos a partir de leite cru, sendo que anteriormente esta comercialização estava condicionada a um período de maturação superior a 60 dias, algo que não ocorre com o queijo tipo Kochkäse. Contudo, há algumas condicionantes na normativa. Uma delas diz que há necessidade de estudos técnicos científicos que comprovem a inocuidade do queijo em questão.

Há, no entanto, o entendimento por parte de técnicos e lideranças de que tais restrições, apesar das razões de ordem sanitária, atendem à lógica da grande indústria, em prejuízo de produtos tradicionalmente produzidos e consumidos no meio rural. Ocorre que a sua pasteurização alteraria o paladar do leite, o que não agrada ao produtor e consumidor, que há muitos anos o consome dessa maneira, sem que tenha causado problemas perceptíveis na área da saúde. Tais restrições, sob o ponto de vista do produtor rural, representam a falta de interesse por parte de políticos para com a manutenção da tradição. Além do Kochkäse, eles reclamam também da proibição de comercialização de outros produtos provenientes da agricultura familiar na região. Esse é o caso do frango caipira e do ovo de galinha que também não podem mais ser vendidos, conforme proibição da Vigilância Sanitária (SILVA, 2013).

Segundo estudos realizados por Silva (2013), na visão dos produtores rurais, o Kochäse é visto como um alimento fácil de preparar, coisa prática, que todos os agricultores poderiam fazer, sem necessidade de uso de máquinas. Nesse contexto, o modo de fazer o Kochkäse, dado a sua simplicidade, não exigia muito trabalho, mas forneceria um importante complemento na alimentação, contribuindo para a diversidade alimentar, justificando sua presença no cotidiano do colono. Ainda segundo Silva (2013), o Kochkäse ressalta a identidade das famílias agricultoras, encontrando-se nele o seu saber e modo de fazer imbricado em seu modo de vida, uma vez que o modelo da agricultura aqui desenvolvido guarda características trazidas das regiões alemãs de origem, onde o gado leiteiro e seus derivados, como a nata, a manteiga, a ricota, o queijo, possuem um papel fundamental no seu sistema alimentar. Além disso, o Kochkäse, além da sua importância para a preservação da identidade e do modo de vida dos agricultores, tem se apresentado como importante fonte de renda.

Como já referido, a tradição do queijo Kochkäse vem desde os primórdios da colonização da região, ainda no século XIX, o que tem levado, nos últimos anos, a iniciativas para providenciar o registro do queijo Kochkäse como Patrimônio Cultural Imaterial do Vale do Itajaí/SC, processo que se encontra em andamento. Paralelamente, estão em andamento estudos e articulações regionais para a construção de um Regulamento de Identidade e Qualidade do Kochkäse, o que permitiria o reconhecimento do produto como Indicação 
Geográfica3. Estão envolvidas nesse processo a Fundação Universidade Regional de Blumenau - FURB, a Empresa de Pesquisa Agropecuária e Extensão Rural (Epagri), prefeituras dos municípios produtores, profissionais da Companhia Integrada de Desenvolvimento Agrícola S/C - Cidasc, dos Serviços de Inspeção Municipal e Vigilância Sanitária e do Ministério da Agricultura. Essas articulações estão ainda em processo de execução, tendo ocorrido durante os anos de 2014 a 2016 (MEISEN, DREWS e MORATELLI, 2015).

Estudos já estão sendo realizados visando à adequação da produção do Kochkäse às normas da Vigilância Sanitária, com vistas a atender o que preceitua a Instrução Normativa $\mathrm{N}^{\circ} 30$ (BRASIL, 2013). Meisen et al. (2015) relatam resultados de estudos realizados com o objetivo de prover subsídios que auxiliem na comprovação da inocuidade do queijo e colaborar no processo de Indicação Geográfica. O procedimento contemplou o acompanhamento do cozimento do queijo em três produtores e verificou-se a contaminação do queijo antes do cozimento e do queijo Kochkäse por aeróbios mesófilos e bolores e leveduras, entre outros aspectos. Os resultados mostraram uma elevada contagem no queijo fermentado e considerável redução da carga bacteriana no Kochkäse. Acreditase que a padronização do processo de cozimento do Kochkäse possa vir a favorecer a inocuidade do produto, controlando-se a temperatura e o tempo de permanência dessa temperatura elevada durante o cozimento.

Por fim, é importante salientar que a alimentação pode tornar-se símbolo de uma identidade, através da qual os homens podem se orientar e se distinguir. Ou seja, o alimento serve para nutrir o corpo, mas também pode sinalizar um pertencimento, servindo como um código de reconhecimento social. Além disso, os alimentos preferidos por um determinado grupo social, em determinada época também, têm relação com a disponibilidade de alimento local. As duas situações podem ser relacionadas ao caso do queijo Kochkäse: fazia parte de uma tradição alimentar e podia ser produzido a partir do leite, alimento abundante entre os produtores rurais.

\footnotetext{
3 Publicação recente aborda o tema em referência, propondose a apresentar indicativos teóricometodológicos para experiências de associativismo territorial que pretendam ascender ao instituto da Indicação Geográfica: Dallabrida (2016).
} 


\subsection{Maricultura e produção de ostras em Florianópolis}

A comercialização de ostras (Crassostrea gigas) no Estado de Santa Catarina se expande a partir do final do século XX, no entorno da ilha de Florianópolis, de 43 em 1993 a 3.030,26 t em 2015. Economicamente, mesmo tendo havido redução de 17,44\% em relação à safra recorde de 2014 (3.670,36 toneladas), a atividade tem uma importância significativa, tendo

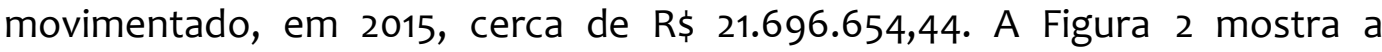
evolução da produção de ostras no Estado, de 1991 a 2015.

Figura 2- Evolução da produção de ostras comercializadas por Santa Catarina entre 1991 e 2015 (t)

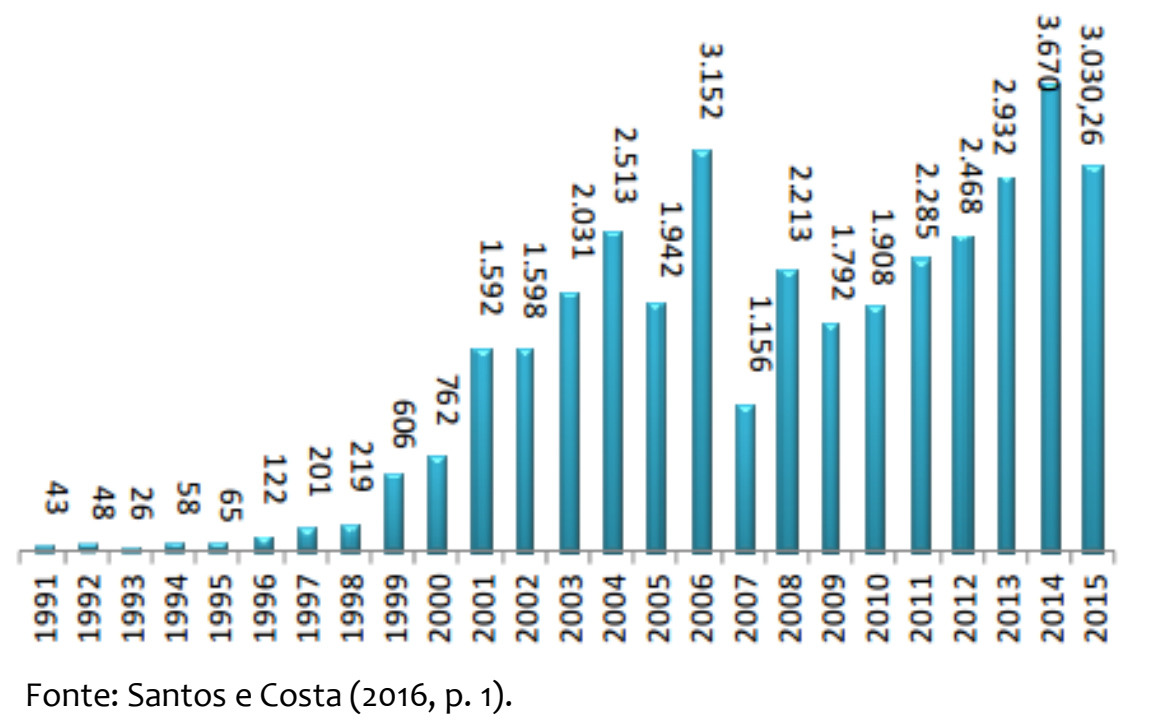

O hábito alimentar de consumir ostra viva restringe o comércio desse produto que deve ser consumido em até 4 dias, mantido sob refrigeração. $O$ comércio brasileiro de ostra viva é praticado, principalmente, via restaurantes e apresenta uma capacidade de absorção de aproximadamente 3.000t/ano. Acima dessa quantidade, as possibilidades de venda diminuem, aumentando a concorrência entre os produtores, diminuindo o preço de venda que atinge valores próximos ao custo de produção, tornando a atividade pouco atrativa. Como solução, atores da cadeia produtiva defendem e apontam estratégias para estimular o comércio de ostras processadas, a exemplo do que ocorre com os mexilhões, elevando o "tempo de prateleira" do produto e permitindo o comércio pelo setor varejista (grandes redes de supermercados), segmento praticamente inexplorado. Assim, a produção de ostra que hoje equivale apenas a 17,44\% da produção de mexilhões se tornaria atrativa para os 572 maricultores do Estado de Santa Catarina e não apenas para os atuais 107 ostreicultores (SANTOS e COSTA, 2016). 
Os municípios que mais contribuíram para a produção total do Estado foram Florianópolis, com uma produção de $2.187,76 \mathrm{t}$, representando uma diminuição de 19,2\% em relação à safra 2014 (2.707,46 t), seguido por Palhoça $(482,0$ t), São José $(225,5$ t) e São Francisco do Sul. Considerando os municípios que se localizam dentro das Baías Norte e Sul, nas proximidades de Florianópolis, equivale dizer que essas Baías são responsáveis por 96,87\% $(2.935,3 \mathrm{t}$ ) da produção estadual de ostras cultivadas $(3.030,26 \mathrm{t}$ ) (SANTOS e COSTA, 2016). Portanto, mais de $90 \%$ da produção de ostras concentra-se na ilha de Florianópolis, sendo o Estado de Santa Catarina responsável por 98\% de toda a produção nacional de moluscos (ANDRADE, 2016).

É fundamental destacar a importância e as implicações socioeconômicas e ambientais da chamada maricultura de bivalves. É comum a superexploração dos oceanos pela atividade da pesca extrativa, o que justifica os volumes de produção estarem em constante declínio em todo o mundo. Assim, sob as necessidades atuais de incremento na produção de alimentos, o mar não pode mais ser visto apenas como um local de coleta, mas, sim, como um campo fértil para o plantio, um oceano de possibilidades. Nesse sentido, a aquicultura representa uma inovadora alternativa ainda não saturada quanto ao incremento da produção de alimento de alta qualidade nutricional. Isso, pois, as sementes plantadas no mar de Santa Catarina, no Brasil, são destinadas à atividade aquícola de malacocultura, nome específico dado à atividade de cultivo de moluscos. Essa é uma forma de maricultura onde não há entrada de alimento ou fertilizantes, sendo este um dos principais custos de outros cultivos. Nessa atividade, dentre os produtos de interesse comercial, destacam-se os moluscos bivalves: mexilhões (Perna perna), a ostra do pacífico (Crassostrea gigas), a ostra nativa (Crassostrea gasar e C. rhizophorae) e as vieiras (Nodipecten nodosus) (ANDRADE, 2016). É o caso da maricultura catarinense.

Estudos técnicos, como os mencionados por Andrade (2016), tem demonstrado serem os moluscos bivalves animais em que cada um é uma pequena unidade filtradora de água. Possuem um sistema para captar a água e fazê-la passar por suas brânquias, que funcionam como um filtro, sendo responsáveis pela respiração e retenção de partículas em suspensão: o fito plâncton, detritos orgânicos e inorgânicos. As partículas retidas são digeridas, uma parte é absorvida e outra eliminada em forma de fezes. O material não ingerido é eliminado. Ambas são reaproveitadas como insumo por plantas aquáticas, crustáceos, micro-organismos e outros animais. A atividade também é tida como uma forma de biossequestro de carbono, incorporando-o em suas conchas por longo período, assim proporcionando mais um impacto positivo e caracterizando-se como um tipo de cultivo benéfico ao meio ambiente. Outro aspecto surpreendente quanto aos bivalves diz respeito à estratégia reprodutiva e sua espetacular capacidade de geração de descendentes, justificado na quantidade de gametas produzidos pelos animais já maduros para reprodução, podendo um casal gerar até 50 milhões de larvas. Devido às condições do meio, apenas uma pequena quantidade é 
reproduzida, sendo, mesmo assim, altamente significativa ${ }^{4}$. Ou seja, a maricultura de moluscos bivalves se justifica por vários fatores favoráveis: o alimento é farto e gratuito no mar, não há necessidade de uso de medicamentos, causa impactos positivos no meio-ambiente e, como acréscimo, os animais têm uma incrível capacidade de reprodução (ANDRADE, 2016).

\section{Figura 3. Produtor de ostras da ilha de Florianópolis}

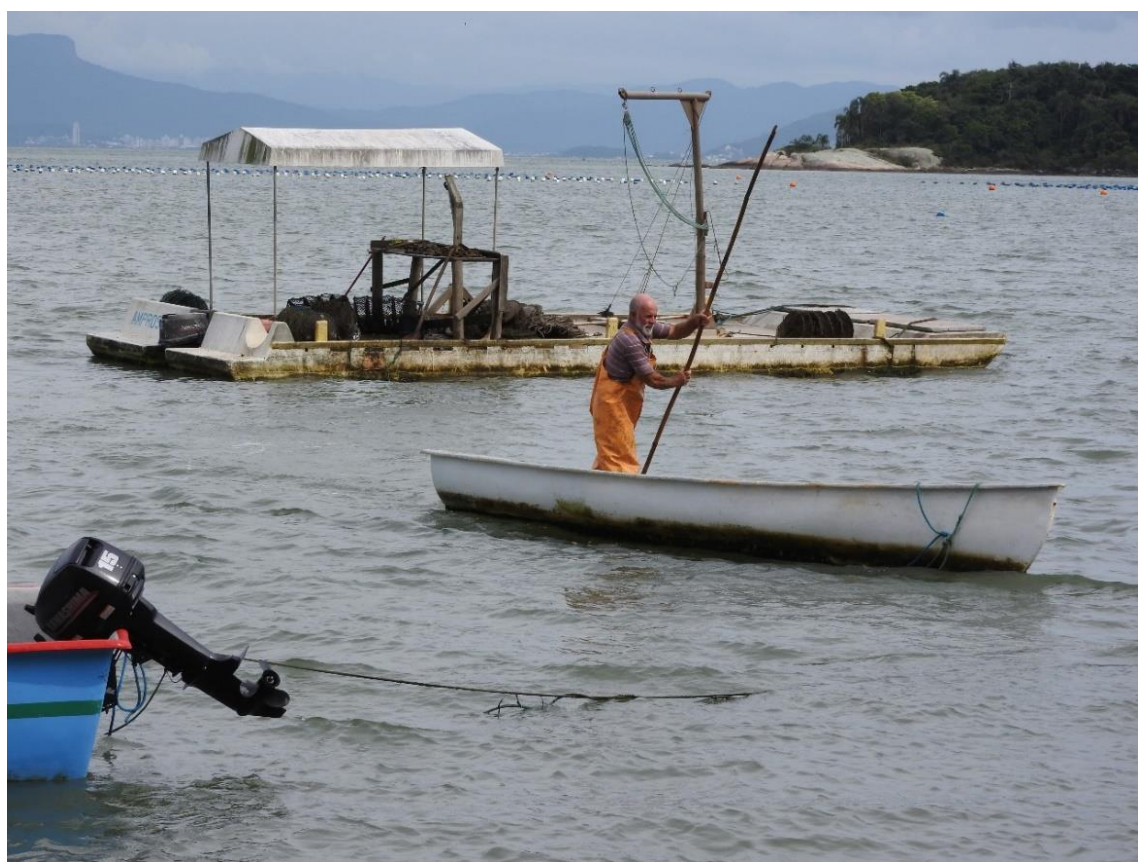

Fonte: Foto de Julio Plaza Tabasco (2016).

Quanto ao impacto econômico da maricultura de ostras na cidade de Florianópolis, maior produtora, Corrêa e Müller (2016) fizeram uma análise no sul da Ilha de Santa Catarina, com o objetivo de analisar a influência da ostra na origem, formação e manutenção da Via Gastronômica do Ribeirão da Ilha - Rota das Ostras. Os resultados obtidos constataram que a maioria dos restaurantes da via só surgiu por causa das ostras. A pesquisa de campo demonstrou que quase $100 \%$ dos clientes que procuram os restaurantes do Ribeirão buscam comer ostra. O molusco sozinho não garante a sobrevivência da via, mas esta é conhecida pela fama de ser o local ideal para se comer ostras.

Já se referindo à promoção do desenvolvimento local, Lins (2016) destaca a atuação da universidade nesse contexto, argumentando ser crucial suas atividades alcançarem o entorno territorial, sobretudo quanto à pesquisa, com transbordamento que transfira conhecimento, estimule a aprendizagem e impulsione a inovação, ajudando a resolver problemas concretos. A relação da Universidade Federal de Santa Catarina UFSC com o cultivo de moluscos na ilha de Florianópolis é
4 Andrade (2016)

menciona alguns destes estudos técnicos sobre o tema aqui apresentado, tais como: Huner \& Brown (1985), Quayle \& Newkirk (1989), Wolf \& Beaumont (2011) e Helm \& Bourne (2004). 
Agricultura familiar, organização de produtores e desenvolvimento territorial: oportunidades e ameaças em experiências agroalimentares no Estado de Santa Catarina (Brasil)

aludido como exemplo bem sucedido de uma projeção universitária com esse perfil. Refere-se ao papel exercido

historicamente pela universidade no estímulo à organização dos maricultores, com aportes tecnológicos integrados às atividades de extensão desenvolvidas por departamentos e cursos afins à área.

A organização dos maricultores de Florianópolis e proximidades é um excelente exemplo de como um trabalho organizado e coordenado entre instituições de pesquisa e extensão podem efetivamente solucionar problemas reais e criar novas possibilidades de trabalho e geração de empregos. Merece destaque o papel exercido pela UFSC, como um elo fundamental para criação e manutenção desta atividade, que, por intermédio do Laboratório de Moluscos Marinhos, tem se concentrado na pesquisa e extensão relacionada à produção de moluscos bivalves, como o caso das ostras (ANDRADE, 2016).

Há formas variadas de organização dos maricultores catarinenses. Uma delas é a Associação de Maricultores e Pescadores Profissionais do Sul da Ilha - Amprosul, formada por pequenos/as produtores/as de ostras e/ou mariscos. Dentre os estudos que existem sobre processos organizacionais na maricultura de ostras, Brito (2012) analisa as formas de interlocução entre os discursos técnico-científicos (governo, pesquisadores, etc.), de um lado, e os dos/as maricultores/as, de outro. A autora mostra que, para as instituições governamentais e parceiras vinculadas à maricultura, diante do objetivo de conciliar desenvolvimento econômico e inclusão social e econômica dos/as produtores/as, a alternativa é transformar o caráter familiar e artesanal das produções: organizá-los/as em associações/cooperativas, profissionalizá-los/as e padronizar suas produções, de modo que possam participar do Arranjo Produtivo Local - APL. Nesse sentido, as políticas públicas dirigidas à maricultura estão voltadas para a organização dos/as produtores/as por meio de associações/cooperativas e a estruturação da cadeia produtiva, do APL. Para os/as maricultores/as, eles desejam ser incluídos/as no mercado, no arranjo, e reclamam do que consideram exigências e normas excessivas, mau uso dos recursos destinados à maricultura e privilégios em relação aos/às "grandes" produtores/as. Entendem que precisam se organizar para que suas demandas sejam atendidas. As falas dos/as maricultores/as indicam a existência de conflitos e de tensões nesse processo de transformação do setor. Ao mesmo tempo, discursos técnico-científicos procuram explicar o porquê das dificuldades de estes/as produtores/as atenderem às novas exigências que se impõem em relação à organização, referindo como causa o fato de não possuírem organização, cooperação/solidariedade. Na análise final, o autor propõe: (i) colocar em questão os discursos técnico-científicos por seu viés economicista, sustentado numa lógica utilitária, espaço para tratar os problemas em termos de exclusão social, econômica e simbólica dos/as pequenos/as produtores/as e refletir sobre a existência de relações de poder assimétricas; (ii) criar outra narrativa sobre os/as produtores/as sem a ênfase na "falta", marcando a importância dos vínculos de amizade e parentesco para eles/as no exercício da atividade, considerando relações de 
trabalho, família e amizade, o que permite que essas pessoas enfrentem as dificuldades que se apresentam.

Essas são as principais análises que consideramos neste artigo para justificar a importância do segmento produtivo como alternativa para a geração de trabalho e renda a pequenos produtores/as do espaço periurbano, o que pode se tornar um importante contributo para o desenvolvimento territorial.

\section{RESULTADOS E ANÁLISES}

Os resultados do trabalho de campo realizado sobre estas experiências agroalimentares no entorno da cidade de Florianópolis refletem as oportunidades e ameaças que se apresentam sobre a agricultura familiar, além da necessidade e interesse de incluílas dentro das estratégias de desenvolvimento territorial, como um modo de diversificação econômica, preservação da identidade territorial, integração social e conservação ambiental, com especial destaque quanto à diferenciação desta região no contexto nacional e internacional.

No caso dos produtores de Kochkäse, a entrevista se realizou com um agricultor de origem alemã, que representa a quarta geração de sua família, casado e com três filhos. Sua propriedade conta com 28 ha de terra, utilizada para plantio de milho, cana de açúcar e gado de leite, com 16 vacas leiteiras, além de um pequeno açude dedicado à piscicultura. Apesar de ser produtor de Kochkäse apreciado na região, suas impressões são negativas quanto ao futuro da criação de gado leiteiro. A ajuda que recebe de seus filhos é muito limitada por vários fatores. Por um lado, o escasso atrativo da vida no espaço rural muito tradicional do ponto de vista cultural e de organização social, frente às oportunidades oferecidas pelos grandes centros urbanos, como Florianópolis, capital de Santa Catarina, com atrativos turísticos e de serviços. Por outro lado, a escassa rentabilidade da exploração agrícola, por sua escassa modernização e integração diferenciada no mercado.

A continuidade desse tipo de exploração agrícola em um entorno dinâmico como é o litoral catarinense depende basicamente da reconversão a novas formas de consumo, associadas aos alimentos diferenciados e ao potencial turístico da região, se bem que no modo de vida desses produtores parece existir um componente de autoconsumo e tradição, que condiciona a inovação e a melhoria de suas condições de vida. Isso os faz depender, em grande medida, das políticas públicas de desenvolvimento rural, que atualmente centram seu foco, basicamente, no controle sanitário do rebanho bovino e dos produtos lácteos, como o queijo cozido Kochkäse. Nas declarações do produtor entrevistado e de membros da família, detecta-se o baixo conhecimento dos mecanismos necessários para melhorar a comercialização de seus produtos no contexto periurbano (novas tipologias de queijos, vasilhame, etiquetas, marketing, etc...), do mesmo modo que as oportunidades que podem surgir do agroturismo (alojamento, educação ambiental, desportes, etc...), em plena expansão no Estado de Santa Catarina. No entanto, segundo depoimento de agentes públicos que acompanharam as 
visitas, várias tentativas de organização do setor e apoio institucional estão ocorrendo nos últimos anos, com tendência de avanços futuros.

Diferente ao caso do queijo Kochkäse, os produtores de ostras são um exemplo evidente de integração na economia periurbana de Florianópolis e de consolidação de suas atividades na oferta agroalimentar e turística regional, não obstante mostrem certas problemáticas que repetem o modelo de fragilidade da agricultura familiar nos contextos periurbanos. $O$ trabalho de campo oportunizou a visita e entrevista a um maricultor da ilha de Florianópolis, casado e com dois filhos, que dedicou toda sua vida à pesca, no entanto, sem tradição familiar anterior em atividades pesqueiras. $O$ interesse pela produção de ostras iniciou-se em princípios dos anos 1990, diante da preocupação pela extração intensiva de pescados e pela degradação das fazendas marinhas.

O setor da maricultura recebeu há mais de dez anos o apoio do governo municipal de Florianópolis, por meio da criação de uma câmara setorial, o que representou uma maior especialização produtiva e maior integração com o turismo urbano. Na transformação e avanços do grupo de maricultores ao qual pertence o produtor visitado, foi ponto de inflexão uma visita oportunizada no litoral da França, com o objetivo de conhecer as formas europeias de cultivo de ostras, as fórmulas de organização, de comercialização e de integração da atividade pesqueira com outras atividades como o turismo. Segundo a pessoa entrevistada, o resultado dessas ações de dinamização e extensão rural foi imediato: além de uma mudança de mentalidade na concepção das fazendas marinhas, suas rendas se multiplicaram em pouco tempo e permitiu uma ampla modernização de suas instalações. No processo de modernização, contribuiu de forma decisiva, também, o apoio técnico do setor especializado da UFSC, com sede em Florianópolis.

Assim, a consolidação da maricultura impulsionou a atividade turística da ilha de Florianópolis, desenvolvendo-se uma gastronomia exclusiva e integrada em um produto turístico. Sem dúvida, outros problemas surgiram em paralelo. Os de tipo ambiental centraram-se na gestão dos resíduos: primeiro, com a demanda dos produtores de ostras para resolver problemas de deposição direta das águas residuais e esgoto no mar, que contaminavam as fazendas marinhas, e posteriormente, com a gestão de resíduos das próprias fazendas, no caso, as conchas das ostras e suas incrustações, além dos materiais utilizados na pesca. O segundo problema centrou-se no associativismo. A competitividade entre produtores frente à demanda do produto por consumidores diretos, no entanto, também por intermediários que distribuíam as ostras nos mercados locais e cidades do litoral, tem prejudicado o movimento associativo inicial, primando os comportamentos individuais. Isso resultou na paralisação dos projetos de reciclagem dos resíduos e de uma central de comercialização que defendesse os interesses dos produtores frente aos atravessadores.

O êxito econômico inicial da maricultura, assim, está ameaçado pelo escasso valor agregado que retêm os maricultores, o que desestimula a sua continuidade na atividade, cujos sucessores, já integrados nas economias 
urbana e turística, rechaçam o trabalho artesanal e o escasso lucro que oferece a atividade até o momento atual.

\section{CONCLUSÕES}

Os estudos realizados para conhecer as trajetórias de distintos tipos de atividade agrícola familiar periurbana na cidade de Florianópolis e cidades próximas, confirmam as oportunidades e ameaças dessas atividades frente ao avanço das cidades em termos de usos do solo e a atração que exerce sobre as populações rurais do ponto de vista social e do emprego, comprometendo sua continuidade. Do mesmo modo, identificam-se as pressões das grandes corporações e intermediários para anular a possível atração que exercem esses produtores, questionando a qualidade sanitária, como foi observado no caso do queijo Kochkäse, ou a capacidade de autogestão e comercialização no caso dos maricultores.

As atividades agrícolas periurbanas aportam qualidade e diferenciação ao processo socioeconômico, com impactos no desenvolvimento territorial, no entanto, suas estruturas carecem de uma adaptação rápida para integrarse de forma competitiva na dinâmica urbano-regional. O caso dos produtores de queijo Kochkäse, apesar de disporem de um produto realmente atrativo às novas demandas agroalimentares, o problema radica-se na falta de inovação e capacidade de empreendimento que imputa a cultura campesina. No caso dos produtores de ostras, o êxito inicial evolui entre grandes incertezas pela competitividade interna e a escassa capacidade de associativismo.

As ações da administração regional e local, para dinamizar e assegurar ambas as economias, têm abordado os problemas mais prementes, que se centram basicamente na garantia sanitária da produção, como no caso do queijo Kochkäse, assegurando a inocuidade frente a determinadas enfermidades, como a tuberculose, e no caso dos maricultores, gestionando adequadamente os dejetos jogados inicialmente ao mar, como os próprios restos de moluscos. Também nesse segundo caso, tem havido preocupação das autoridades locais por sua associação em vistas à promoção turística da cidade e a gestão dos resíduos.

Em ambos os casos, e apesar dos esforços públicos, ainda não se tem produzido a organização territorial dos produtores adequada, com o fim de contribuir para a identificação de sua produção como signos distintivos territoriais, o que asseguraria a sua participação no processo de modernização econômica e social, além de oportunizar o acesso aos mercados de consumo de produtos diferenciados.

Por fim, entende-se que o presente tema necessita de avanços, como a necessidade de analisar experiências desse tipo com o propósito de avaliar suas potencialidades reais de constituírem-se em signos distintivos territoriais, o que está previsto, na sequência, por meio de novas ações de investigação do grupo. 
Agricultura familiar, organização de produtores e desenvolvimento territorial: oportunidades e ameaças em experiências agroalimentares no Estado de Santa Catarina (Brasil)

\section{REFERÊNCIAS}

ANDRADE, G. J. P. O. Maricultura em Santa Catarina: a cadeia produtiva gerada pelo esforço coordenado de pesquisa, extensão e desenvolvimento tecnológico. Extensio: R. Eletr. de Extensão, Florianópolis, v. 13, n. 24, p. 204217, 2016.

AVILA, $\mathrm{H}$. La agricultura en las ciudades y su periferia: un enfoque desde la Geografía, Investigaciones Geográficas de la Universidad de México, n. 53, 2004 .

BRASIL. Ministério do Estado de Agricultura, Pecuária e Abastecimento. Departamento de Inspeção de Produtos de Origem Animal. Portaria $\mathbf{N}^{\circ} \mathbf{3 0}$, de 07 de agosto de 2013. Permite a produção de queijos artesanais elaborados a partir de leite cru. Diário Oficial da União, Brasília, 08 de agosto de 2013.

BRITTO, R. A. Trabalho, família e amizade entre maricultores/as de uma associação do sul da ilha de Florianópolis: a Amprosul. Tese (Doutorado), Programa de Pós-Graduação em Antropologia Social da Universidade Federal de Santa Catarina. Florianópolis: UFSC, 2012.

CAPEL, H. Las geografía y las periferias urbanas. Reflexiones para arquitectos. Antrophos: Boletin de información y documentación, n. Extra 43, p. 136-143, 1994 (Exemplar dedicado a: La geografía hoy. Textos, historia y documentación).

CARTA DE LA AGRICULTURA PERIURBANA. Para la preservación, la ordenación, el desarrollo y la gestión de los espacios agrarios periurbanos (2010). Castelldefels (Espanha), septiembre de 2010.

COMITÉ ECONÓMICO Y SOCIAL EUROPEO. Dictamen del Comité Económico y Social Europeo sobre “la agricultura periurbana”. Bruselas: CESE, 2004.

CORRÊA, A. J.; MÜLLER, S. G. A influência da ostra na origem, formação e manutenção da via gastronômica do Ribeirão da llha - rota das ostras Florianópolis-SC. Ágora, Santa Cruz do Sul, v. 18, n. 01,p. 119-130, jan./jun. 2016.

DALLABRIDA, V. R. Território, Governança e Desenvolvimento Territorial: indicativos teórico-metodológicos, tendo a Indicação Geográfica como referência. São Paulo: LiberArs, 2016.

DALLABRIDA, V. R.; RUÍZ, Á. R.; PLAZA, J. J. Signos Distintivos Territoriais, Indicação Geográfica e Desenvolvimento Territorial: uma primeira apreciação sobre experiências na Espanha e Brasil. In: IX Encontro Nacional de Pesquisadores em Gestão Social/ENAPEGS, Anais..., Porto Alegre (RS-Brasil), UFRGS,19 a 21 de maio de 2016. 
GÓMEZ MENDOZA, J. La agricultura periurbana: su estudio, sus cambios, sus políticas. Agricultura y sociedad, nº 42, p. 109-146, 1987.

LINS, H. N. Universidade e desenvolvimento local ou regional: aspectos do debate e abordagem de uma experiência em Santa Catarina. Ensaios FEE, Porto Alegre, v. 37, n. 3, p. 801-824, dez. 2016.

MEISEN, M. N. et al. Análises Microbiológicas do queijo Kochkäse em Diferentes Processos. In: Segundo Congresso Sul Brasileiro de Engenharia de Alimentos, Anais..., Blumenau, 2015.

MEISEN, M. N.; DREWS, A.; MORATELLI, N. F. Avaliação Microbiológica do processo de cozimento do queijo Kochkäse visando contribuir com a prerrogativa de inocuidade da IN30 do Ministério da Agricultura. Relatório de Pesquisa, com financiamento do IPHAN. Blumenau: FURB, 2015.

PECQUEUR, B. A guinada territorial da economia global. Política \& Sociedade, n. 14, p. 79-105, abril/2009.

RUÍZ Á. R.; PLAZA J. J. Distintivos de calidad agroalimentaria en Castilla-La Mancha (España). Influencia de la escala en la gobernanza territorial.

Desenvolvimento Regional em debate, v. 5, n. 2, p. 48-70, jul./dez. 2015.

SANTOS, A. A.; COSTA, S. W. Síntese Informativa da Maricultura 2015.

Florianópolis: EPAGRI, 2016 (Centro de Desenvolvimento em Aquicultura e Pesca - Cedap).

SEGRELLES, J. A. Agricultura periurbana, parques naturales agrários y mercados agropecuários locales: una respuesta territorial y productiva a la subordinación del campo a la ciudad. Scripta Nova, Vol. XIX, n. 502, 2015.

SILVA, M. C. G. O Kochkäse como produto tradicional feminino e seu inventário como patrimônio cultural imaterial do Vale do Itajaí/SC. Seminário Internacional Fazendo Gênero, Anais Eletrônicos, Florianópolis (SC), 2013.

SILVA, M. C. G. O Kochkäse e suas controvérsias como produtor de identidade, saúde e renda entre agricultores familiares do Vale do Itajaí (SC). In: PINHEIRO, J.; SOARES, C. (Coords.). Patrimónios Alimentares de Aquém e Além-Mar. Coimbra (PT): Imprensa da Universidade de Coimbra/Annablume, 2016, p. 63-89.

YACAMAN, C. y MATA, R. La gobernanza territorial y alimentaria como base para la protección y dinamización del espacio agrario periurbano. Estudio de caso del parque agrario de Fuenlabrada (comunidad de Madrid). En: XVII Coloquio de Geografía Rural de la Asociación de Geógrafos Españoles, Anais... Girona, Univ, Girona, p. 275-288. 
Agricultura familiar, organização de produtores e desenvolvimento territorial: oportunidades e ameaças em experiências agroalimentares no Estado de Santa Catarina (Brasil)

Valdir Roque Dallabrida. Geógrafo, Doutor em Desenvolvimento Regional pela UNISC, pesquisador do CNPq Produtividade em Pesquisa, com atuação no programa de Mestrado em desenvolvimento Regional da Universidade do Contestado - Santa Catarina-Brasil. valdirdallabrida@gmail.com

Julio José Plaza Tabasco. Doutor em Geografia, com atuação no Departamento de Geografía y Ordenación del Territorio da Universidad de Castilla-La Mancha, Ciudad Real, Espanha. julio.plaza@uclm.es

Ángel Raul Ruíz Pulpón. Doutor em Geografia, com atuação no Departamento de Geografía y Ordenación del Territorio da Universidad de Castilla-La Mancha, Ciudad Real, Espanha. angelraul.ruiz@uclm.es 